\title{
Pneumatose Cística Intestinal
}

\section{Pneumatosis Cystoides Intestinalis}

\author{
VALDEMIR JOSÉ ALEGRE SALLES ${ }^{1}$;EDUARDO SABA ${ }^{2}$; ANTONIO BAPTISTACAUDURO³; \\ FELIPECAUDUROSALGADO ${ }^{4}$
}

\begin{abstract}
1 Professor Mestre Assistente da Disciplina da Clínica Cirúrgica da Universidade de Taubaté; 2 Professor Assistente da Disciplina de Técnica Operatória da Universidade de Taubaté; 3 Professor Doutor Emérito da Disciplina da Clínica Cirúrgica da Universidade de Taubaté; 4 Cirurgião Geral do Hospital São Lucas de Taubaté.
\end{abstract}

\begin{abstract}
SALLES VJA; SABA E; CAUDURO AB; SALGADO FC. Pneumatose Cística Intestinal. Rev bras Coloproct, 2008;28(2): 238-240.
RESUMO: Pneumatose cística intestinal é uma doença rara caracterizada pelo acúmulo de gás na parede intestinal estando associada a uma variedade de doenças e procedimentos. Não existe uma história específica, achados de exame físico ou laboratorial que auxiliam no diagnóstico. $O$ tratamento conservador utilizando-se a oxigenioterapia hiperbárica é efetivo, ficando a abordagem cirúrgica indicada quando há complicações.
\end{abstract}

Descritores: Pneumatose cística, Doença de Crohn, Pneumoperitônio, Pneumatose intestinal.

\section{INTRODUÇÃO}

A pneumatose cística intestinal é uma doença rara, caracterizada pela presença de múltiplos cistos gasosos na parede intestinal, comprometendo a camada subserosa e submucosa ${ }^{(1,2,3)}$, sendo encontrada no intestino delgado em $42 \%$, no intestino grosso em $36 \%$ e difusamente em $22 \%$ (4). Pode ter manifestação clínica isolada em $25 \%$ dos casos, quando recebe a denominação de pneumatose cística intestinal primária ${ }^{(5)}$ e quando está associada à outra doença é considerada como secundária, apresentando-se ainda como assintomática ou com graus variáveis de severida$\mathrm{de}^{(6)}$, podendo ser aguda ou subaguda ${ }^{(3)}$. Acomete o sexo masculino numa freqüência três vezes maior ${ }^{(3)}$, com maior frequiência na faixa etária adulta sendo mais rara na infância (7). Ao exame histológico o acometimento da parede intestinal faz-se sob a forma de microvesículas ou pseudolipomatose mucosa, cística ou difusa ${ }^{(8)}$.

\section{CASO CLÍNICO}

Paciente de 32 anos, masculino, portador de Doença de Crohn, em tratamento clínico há quatro anos com corticosteróide e mesalazina, foi admitido no Serviço de Emergência apresentando um quadro de distensão abdominal associado a empachamento, diarréia, vômitos e febre, com evolução clínica de dois dias, tendo piora no seu estado geral neste período.

Apresentava-se em regular estado, subfebril e discretamente desidratado. Ao exame abdominal não foram encontradas alterações significativas, sendo submetida a exames subsidiários para elucidação diagnóstica. A avaliação laboratorial não foi conclusiva, apresentando discreta leucocitose, hipopotassemia e elevação da creatinina sérica. No exame radiológico de rotina para abdômen agudo, ficou evidente a presença de um volumoso pneumoperitônio bilateral (figura 1), associado à distensão jejuno-ileal. O doente foi submetido à laparotomia exploradora evidenciando-se uma área de estenose, com cerca de dez centímetros 
de extensão, acometendo o íleo distal (figura 2), associado a incontáveis lesões císticas gasosas dispersa no jejuno e íleo (figura 3), sem secreção intra-peritoneal ou perfuração intestinal, sendo realizada enterectomia da lesão estenosante.

\section{DISCUSSÃO}

O desenvolvimento da pneumatose cística intestinal pode estar associado à doença de Crohn ${ }^{(9,10)}$, patologia gastrointestinal e pulmonar, colagenase, AIDS, transplantados, agentes imunossupressores ${ }^{(5,10,11)}$, e a procedimentos endoscópicos que lesem a mucosa, como a polipectomia ou biópsia de mucosa intestinal ${ }^{(5)}$.

$\mathrm{Na}$ etiopatogenia da pneumatose cística intestinal deve-se levar em consideração a existência de quatro teorias, a mecânica, a bacteriana, a pulmonar e

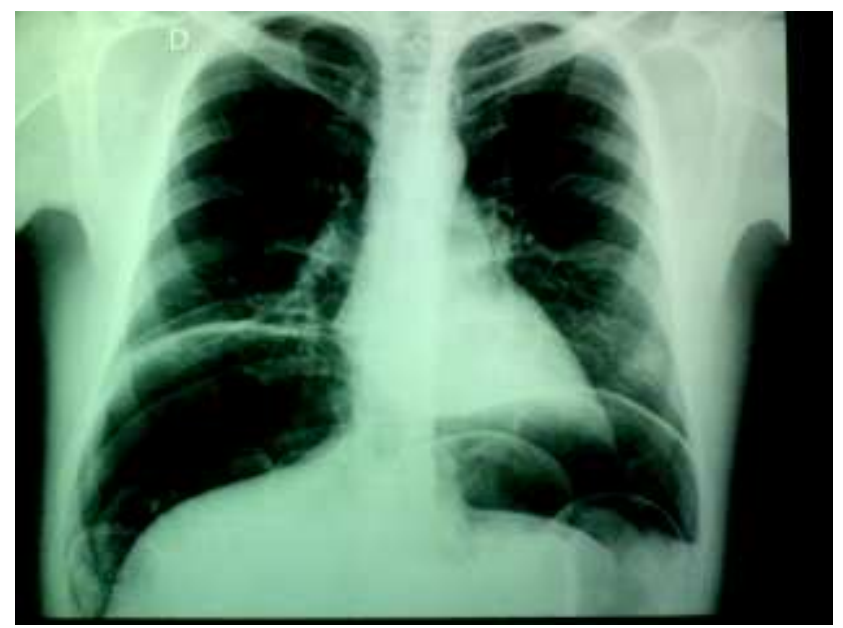

Figura 1

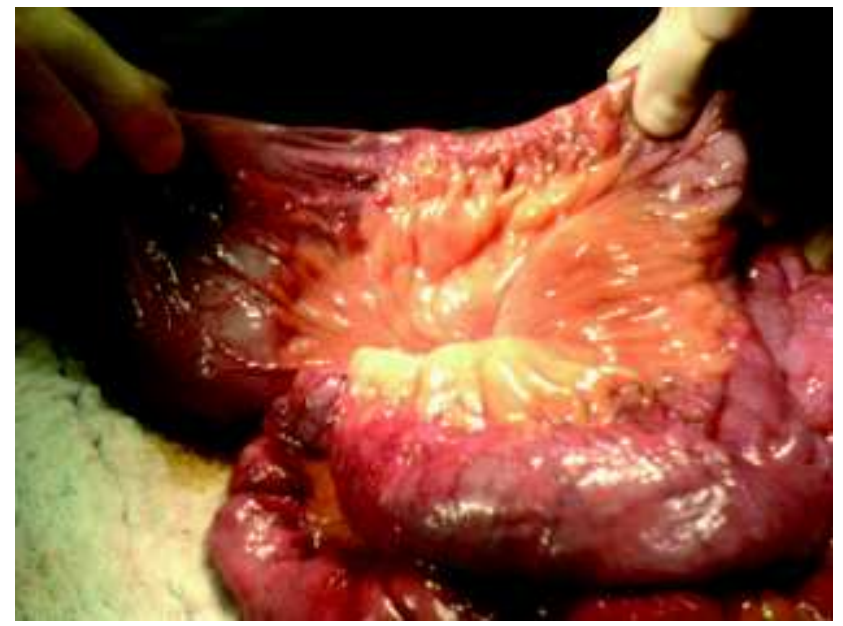

Figura 2 a que se refere a lesão da mucosa intestinal ${ }^{(3,12)}$. $\mathrm{Na}$ teoria mecânica correlaciona-se o efeito mecânico do aumento da pressão dos gases no espaço intraluminal sob a parede, geralmente acometendo os locais em que há um defeito na continuidade da mucosa, como no trauma, em cirurgias, endoscopias e nos casos de obstrução intestinal ${ }^{(12)}$, em crianças encontramos associação com a estenose hipertrófica do piloro e a doença de Hirschprung ${ }^{(7,12)}$. A teoria bacteriana baseia-se no conceito da produção de gases, principalmente o hidrogênio, por bactérias anaeróbias presentes no lúmen intestinal ${ }^{(7,12)}$, sendo confirmada em estudos experimentais pela aplicação intramural de bactérias ${ }^{(13)}$. Na teoria pulmonar ocorreria uma ruptura dos alvéolos seguido da difusão gasosa pelo mediastino e retroperitônio ao longo dos vasos até a parede intestinal ${ }^{(12)}$. Especula-se que haja uma associação entre a elevação da pressão intraluminal, lesão da mucosa e proliferação de bactérias produtoras de gás na parede intestinal formando os cistos ${ }^{(1,3)}$.

A apresentação clínica pode ser frustra, pouco sintomática, apresentando um discreto desconforto abdominal ou com perda sanguínea fecal ${ }^{(6)}$, enfisema subcutâneo ${ }^{(11)}$, até quadros mais graves em que se observa a presença de isquemia intestinal, gás no plexo venoso portal e mesentérico, acidose metabólica e sepsis abdominal $^{(1)}$.

Ao exame radiológico simples, o achado do pneumoperitônio mimetiza a perfuração intestinal ${ }^{(1)}$, podendo ser observado ainda o pneumomediastino, pneumoretroperitonio ${ }^{(11)}$ e a presença de gás infiltrando a parede intestinal ${ }^{(4)}$. Durante o exame endoscópico

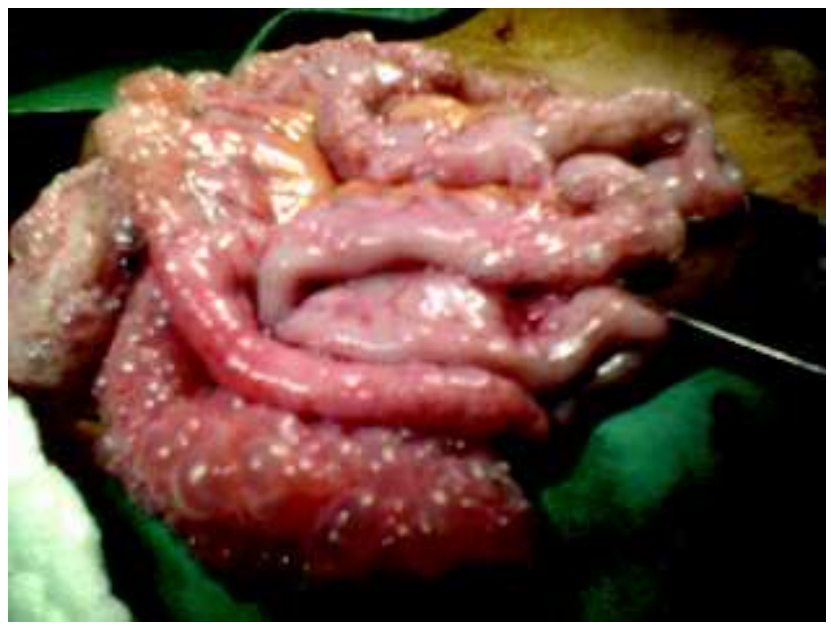

Figura 3 
evidencia-se lesões de características polipóides que ao serem biopsiadas colabam devido à saída de gás ${ }^{(3)}$.

O tratamento é inicialmente clínico conservador, com sintomáticos suporte hemodinâmico e hidroeletrolítico, antibióticoterapia, tendo uma boa resolução através da oxigenoterapia hiperbárica ${ }^{(2,5)}$. Nos casos em que o tratamento conservador não é efetivo ou quando há uma piora progressiva do quadro clínico a intervenção cirúrgica se impõe, por meio de videolaparoscopia $^{(2)}$ ou por laparotomia exploradora ${ }^{(1,2)}$.

O diagnóstico diferencial envolve as diversas doenças determinantes de perfuração intestinal ${ }^{(1)}$, tendo uma morbi-mortalidade elevada nos casos de enterocolite necrotizante ${ }^{(7)}$, isquemia e necrose intestinal ${ }^{(2,14)}$, havendo uma alta mortalidade quando constatado gás no plexo venoso portal. ${ }^{(14)}$.

ABSTRACT: Pneumatosis cystoides intestinalis is an uncommon disease characterized by an accumulation of gas in the bowel wall, and has been associated with a variety of disorders and procedures. There is no specific history and physical or laboratory findings do not help to diagnose. The treatment conservative with hyperbaric oxygen is effective, and surgery is usually indicated when complications appear.

Key words: Pneumatosis cystoids, Crohn's disease, Pneumoperitoneum, Pneumatosis intestinalis.

\section{REFERÊNCIAS}

1. Keam B, Lee JH, Oh MD, Kim I, Yoon SS, Kim BK, Park S. Pneumatosis intestinalis with pneumoperitoneum mimicking intestinal perforation in a patient with myelodisplastic syndrome after hematopoietic stem cell transplantation. Korean J Intern Med 2007;22(1):40-4.

2. Kala Z, Hemanova M, Kysela P. Laparoscopically assisted subtotal colectomy for idiopathic pneumatosis cystoides intestinalis. Acta Chir Belg 2006;106(3):346-7.

3. Rennenberg RJMW, Koek GH, Van Hootegem P, Stockbrügger RW. Pneumatosis cystoids intestinalis, four cases of q rare disease. Neth J Med 2002 Mar; 60(1):22-5.

4. Jamart J. Pneumatosis cystoids intestinalis. A statistical study of 919 cases. Acta Hepato Gastoenterol 1979;26:419-22.

5. Furio L, Vergura M, Russo A, Bisceglia N, Talarico S, Gatta R, Tomaiuolo M, Tomaiuolo P. Pneumatosis coli induced by acarbose administration for diabetes meliitus. Case report and literature review. Minerva Gastroenterol Dietol 2006;52(3):339-46.

6. Gagliardi G, Thompson IW, Hershman MJ, Forbes A, Hawley PR, Talbot IC. Pneumatosis coli: a proposed pathogenesis based on study of 25 cases and review of the literature. Int $\mathbf{J}$ Colorect Dis 1996;11:111-8.

7. Llerena RP, Gómez JG, Valdez CL, Uzieda LG, Hinojosa RF, Ampuero JM, Rodriguez NR. Neumatosis quística intestinal: a propósito de un caso. Rev Soc Bol Ped 2004;43(1):15-7.
8. Cunnion KJ. Pneumatosis intestinalis in pediatric acquired immunodeficiency syndrome. Pediatr Infect Dis J 1998;17:355-6.

9. Galandiuk S, Fazio VW, Petras RE. Pneumatosis cystoides intestinalis in Crohn's disease. Report of two cases. Dis Colon Rectum 1985 Dec;28(12):951-6.

10. John A, Dickev K, Fenwick J, Sussman B, Beeken W. Pneumatosis intestinalis in patients with Crohn's disease. Dig Dis Sci1992 Jun;37(6):813-7.

11. Saito M, Tanikawa A, Nakasute K, Tanaka M, Nishikawa T. Additive contribution of multiple factors in the development of pneumatosis intestinalis: a case report and review of the literature. Clin Rheumatol 2007;26(4):601-3.

12. Tang MLK, Williams LW. Pneumatosis intestinalis in children with primary combined immunodeficiency. J Pediatr 1998; 132:546-9.

13. Santos Jr JCM. Pneumatose cistóide intestinal. Rev bras Coloproct 1998;18(4):262-4.

14. Knechtle SJ, Davidoff AM, Rice RP. Pneumatosis intestinalis: surgical management and clinical outcome. Ann Surg 1990;212:160-5.

\section{Endereço para correspondência: VALDEMIR JOSÉ ALEGRE SALLES \\ Rua José Bonani, 199 \\ Independência, Taubaté, São Paulo \\ CEP: 12031-260 \\ E-mail: valiris@vivax.com.br}

